\title{
STUDI META ANALISIS EFEKTIVITAS CBT UNTUK KECEMASAN PADA GANGGUAN BIPOLAR
}

\author{
Ivana Jessline $^{1}$, Monty P. Satiadarma ${ }^{2}$, Rita Markus Idulfilastri ${ }^{3}$ \\ ${ }^{1}$ Jurusan Program Studi Magister Psikologi Profesi, Universitas Tarumanagara Jakarta \\ Email: Ivana.717182008@stu.untar.ac.id \\ ${ }^{2}$ Fakultas Psikologi, Universitas Tarumanagara Jakarta \\ Email:montys@fpsi.untar.ac.id \\ ${ }^{3}$ Fakultas Psikologi, Universitas Tarumanagara Jakarta \\ Email:ritamarkus@fpsi.untar.ac.id
}

Masuk : 26-04-2021, revisi: 26-04-2021, diterima untuk diterbitkan : 29-10-2021

\begin{abstract}
Bipolar affective disorder (bipolar) is a multicomponent disease involving episodes of severe mood disorders, neuropsychological deficits, immunological and physiological changes, and impairments in functioning.In addition to being characterized by episodes of mania, hypomania, depression, and a mixed state of the three, often followed by high rates of comorbidity with other mental illnesses. One of the therapeutic alternatives offered is with psychotherapy with cognitive behavior therapy $(C B T)$. CBT is best form of psychoteraphy choosen that is used to treat anxiety in people with bipolar disorder. Nevertheless, the results obtained are still not consistent and can be generalized. The purpose of this study was to determine the overall difference in anxiety disorders in bipolar patients after being given CBT and the significance effect. The research method is a meta-analysis. The articles used are searched from various databases and selected using PRISMA. The results of the synthesis and processing of data showed that there were differences in symptoms of anxiety disorders after being given CBT and the overall point effect size estimate was 0.89 with $p<0.05$ indicating a high effect, thus giving a conclusion that CBT was effective for use as a therapy to overcome anxiety in bipolar disorder. Limitations and suggestions for further research, especially control of sampling. Strengths, limitations, and the need for future research are discussed.
\end{abstract}

Keywords: Cognitive behavior, therapy, anxiety, bipolar, meta-analysis

\begin{abstract}
ABSTRAK
Gangguan afektif bipolar (bipolar) adalah penyakit multikomponen yang melibatkan episode gangguan mood yang parah, defisit neuropsikologis, perubahan imunologis dan fisiologis, dan gangguan dalam keberfungsian. Selain ditandai dengan adanya episode mania, hipomania, depresi, serta keadaan campuran dari ketiganya, seringkali diikuti oleh tingginya angka komorbiditas dengan penyakit mental lainnya. Salah satu alternatif terapi yang ditawarkan adalah dengan psikoterapi dengan cognitive behavior therapy (CBT). CBT menjadi salah satu pilihan psikoterapi yang digunakan untuk mengatasi kecemasan pada penderita bipolar. Namun demikian, hasil yang didapatkan masih belum konsisten dan dapat digeneralisasi. Tujuan dari penelitian ini adalah untuk mengetahui secara keseluruhan perbedaan gangguan kecemasan pada pasien bipolar setelah diberikan CBT dan seberapa besar efeknya. Metode penelitian adalah meta analisis. Artikel yang digunakan dicari dari berbagai database dan dipilih dengan menggunakan PRISMA. Hasil sintesis dan pengolahan data menunjukan ada perbedaan gejala gangguan kecemasan setelah diberi CBT. Hasil statistik menunjukan signifikansi yang tinggi dan estimasi poin effect size menyeluruh adalah 0,89 dengan signifikansi $\mathrm{p}<0.05$ mengindikasikan efek yang tinggi, sehingga memberi kesimpulan CBT efektif untuk digunakan sebagai terapi mengatasi kecemasan pada bipolar. Keterbatasan dan saran untuk penelitian selanjutnya yaitu control yang dilakukan pada saat melakukan sampling. Kekuatan, keterbatasan, dan kebutuhan untuk penelitian masa depan juga dibahas.
\end{abstract}

Kata Kunci : Cognitive behavioral, terapi, kecemasan, bipolar, meta analisis

\section{PENDAHULUAN}

\section{Latar Belakang}

Gangguan afektif bipolar (bipolar) adalah penyakit multikomponen yang melibatkan episode gangguan mood yang parah, defisit neuropsikologis, perubahan imunologis dan fisiologis, dan gangguan dalam keberfungsian (Marwaha et al., 2013, dalam Rowland \& Marwaha, 2018). Pada 
tahun 2013, DSM V mencatat bahwa prevalensi gangguan bipolar I berkisar antara 0-0.6\% dan secara internasional prevalensi bipolar II adalah sebesar 0,3\% (American Psychiatric Association, 2013). Namun penelitian terbaru mencatat gangguan bipolar memiliki prevalensi global sebesar 1-4\% (Loftus et al., 2020). Gangguan bipolar adalah penyakit yang melumpuhkan karena onset awal, keparahan dan kronisitasnya (Wilkowska \& Cubała, 2019). Faktanya, bipolar merupakan penyebab disabilitas ke-6 di dunia (Ferrari et al., 2016).

Gangguan bipolar selain ditandai dengan adanya episode mania, hipomania, depresi, serta keadaan campuran dari ketiganya, seringkali diikuti oleh tingginya angka komorbiditas dengan penyakit mental lainnya yaitu hingga $97.7 \%$ pasien bipolar menerima diagnosis gangguan kejiwaan seumur hidup tambahan (Kinrys et al., 2019). Komorbid didefinisikan sebagai kehadiran lebih dari satu gangguan pada seseorang dalam periode waktu yang ditentukan (Wittchen, 1996 dalam Spoorthy et al., 2019). Di antara semua komorbiditas potensial, komorbid gangguan kecemasan menjadi menonjol karena prevalensi yang tinggi (Nabavi et al., 2015).

Tingkat komorbiditas gangguan kecemasan pada bipolar tidak hanya beberapa kali lipat lebih tinggi dari tingkat populasi umum gangguan kecemasan, tetapi juga lebih tinggi dari yang ditemukan pada gangguan unipolar (Freeman, 2002; Issler, 2004; Kauer-Sant'Anna, 2009 dalam Spoorthy et al., 2019) dan skizofrenia (Somers, 2006; Achim, 2011 dalam Spoorthy, Chakrabarti \& Grover, 2019). Secara spesifik, komorbiditas gangguan kecemasan pada penderita bipolar I adalah sebesar 86\% dan 89\% pada bipolar II (Merikangas et al.,2007 dalam Kinrys et al, 2019). Sederhananya, hampir satu dari dua penderita bipolar memiliki diagnosis seumur hidup setidaknya satu gangguan kecemasan (Pavlova et al, 2015). American Psychological Association dalam DSM V (2013) mencatat bahwa gangguan kecemasan merupakan gangguan komorbid yang paling tinggi (75\%) dialami oleh penderita bipolar selain dari gangguan ADHD, gangguan impulsif atau conduct disorder (APA, 2013). Hal ini diperkuat dengan adanya studi epidemiologi yang menunjukkan bahwa komorbid kecemasan mungkin merupakan kondisi komorbid yang paling umum pada penderita bipolar dan bahkan lebih umum dibandingkan dengan komorbid penyalahgunaan zat (Yapici et al., 2018), serta lebih tinggi angka kejadiannya daripada penyalahgunaan alkohol atau gangguan kepribadian (Jones et al., 2018).

Kecemasan bisa ditimbulkan karena adanya rangsangan yang berasal dari luar atau rangsangan dari dalam yang diterima dan diinterpretasikan sebagai bahaya atau ancaman (Adriani \& Satiadarma, 2011). Kecemasan adalah emosi yang terdiri dari pikiran-pikiran tidak menyenangkan, sensasi tidak menyenangkan, dan perubahan fisik yang terjadi dalam menanggapi situasi atau stimulus yang dianggap mengancam atau berbahaya (Tania, 2014 dalam Subroto et al., 2017). Perasaan tidak menyenangkan ini biasanya samar-samar dan sulit dipastikan, tetapi selalu dapat dirasakan (Subroto et al., 2017). Beberapa penelitian menekankan hubungan yang bersifat destruktif antara gangguan kecemasan pada penderita bipolar, yaitu membuat penderita bipolar mengalami tingkat keparahan yang lebih tinggi, gangguan yang lebih besar (Ellard et al., 2017), besarnya angka kejadian untuk kambuh (Simon et al., 2004; Sala et al., 2012; Hawke et al., 2013 dalam Jones et al., 2018), memperburuk regulasi emosi (Ellard, 2018), gangguan depresi yang lebih parah (Simon et al. 2004; Gaudiano \& Miller, 2005; O'GarroMoore et al. 2015 dalam Jones et al., 2018), tingginya penyalahgunaan zat (Boylan et al. 2004; Simon et al. 2004; Gao et al. 2010), kurang respon terhadap penanganan pengobatan (Henry et al., 2003 dalam Schaffer, 2015; Ellard, 2018), meningkatnya ide dan angka percobaan bunuh diri (Simon et al., 2004; Goes et al., 2012; Thibodeau et al., 2013 dalam Schaffer et al., 2015), periode euthymia yang semakin pendek (Latalova, 2013), dan meningkatkan impulsivitas (Bellani, 2012). Selain itu, komorbid gejala dan gangguan kecemasan memiliki efek yang 
signifikan pada presentasi klinis dan pendekatan treatment untuk pasien gangguan mood (Schaffer et al., 2012).

Dengan tingginya prevalensi, serta efek yang ditimbulkan komorbid kecemasan pada penderita bipolar tersebut, maka dibutuhkan treatment yang tepat. Namun sayangnya, berbagai sumber masih menyatakan bahwa tidak ada studi intervensi yang dirancang dengan baik (Latalova et al., 2013); penelitian pengembangan pengobatan yang efektif masih sangat langka (Mitchell, 2015); perawatan yang ada sejauh ini tidak cukup dalam memenuhi kebutuhan untuk mengatasi kecemasan dalam konteks bipolar (Vazquez et al., 2014 dalam Ellard et al., 2017); serta belum ada intervensi psikologis spesifik yang ditargetkan pada kecemasan dalam konteks bipolar (Jones et al., 2018).

Salah satu alternatif yang ditawarkan adalah dengan psikoterapi. Penelitian menunjukan bahwa gangguan kecemasan komorbid seumur hidup lebih banyak kemungkinan sembuh dengan psikoterapi daripada dengan perawatan kolaboratif (Deckersbach et al., 2014). Tantangannya adalah tidak seperti komorbid kecemasan pada bipolar, gangguan kecemasan sudah secara jelas dan efektif ditangani secara psikoterapi dengan cognitive behavioral therapy (CBT) (Stratford et al., 2015). Bahkan sebuah penelitian meta analisis mengungkapkan bahwa CBT mampu menurunkan simptom kecemasan dalam 12 bulan penanganan (van Dis et al., 2020). Meskipun perawatan CBT juga direkomendasikan sebagai pilihan pengobatan yang pertama, basis bukti untuk perawatan perilaku kognitif sangat sedikit hingga saat ini. Hanya sedikit uji coba terkontrol acak baru dari perawatan CBT telah menunjukkan efektivitasnya dalam mengobati gejala kecemasan pada bipolar, sehingga menjadikannya pilihan yang sah untuk pengobatan bersamaan gangguan kecemasan pada bipolar (Spoorthy et al., 2019). Walaupun demikian, efektivitasnya masih belum teruji secara jelas baik dari desain penelitian, kuantitas subjek maupun hasil treatment. Sehingga diperlukan evaluasi menyeluruh dari semua penelitian yang ada untuk mengevaluasi penelitian secara menyeluruh guna mengetahui efektivitas sebuah terapi biasa dilakukan meta analisis.

Meta-analisis adalah teknik standar untuk mensintesis berbagai studi pada topik yang sama, dan didefinisikan sebagai "analisis statistik dari sekumpulan besar hasil analisis dari studi individual untuk tujuan mengintegrasikan temuan (Glass, 1976 dalam Van Aert, 2019). Kajian meta analisis meningkatkan jumlah sampel sehingga berdampak pada kekuatan efek studi dengan menggabungkan studi utama sambil mempertimbangkan ukuran sampel dari penelitianpenelitian yang diikutsertakan (Walker, 2008 dalam Lee, 2019). Data yang disintesis dari metaanalisis biasanya lebih bermanfaat daripada hasil tinjauan naratif, karena yang hasil tinjauan naratif memiliki banyak kelemahan yang dapat diatasi dengan meta-analisis (Cooper, 1980 dalam Lee, 2019). Meta analisis telah digunakan terutama dalam bidang ilmu sosial khususnya psikologi dan juga secara luas digunakan dalam bidang biologi dan kedokteran (Stone \& Rosopa, 2017). Melalui meta analisis, dapat diperoleh hasil penelitian yang lebih komprehensif dan memiliki kekuatan untuk melakukan generalisasi dengan lebih baik. Dengan dasar pertimbangan keuntungan tersebut, maka penelitian ini akan menggunakan metode kajian meta analisis untuk mengetahui efektivitas CBT dalam menangani kecemasan pada penderita bipolar

\section{Rumusan Masalah}

CBT menjadi salah satu pilihan psikoterapi yang digunakan untuk mengatasi kecemasan pada penderita bipolar. Walaupun CBT sudah terbukti mampu menurunkan kecemasan pada penderita bipolar, hasil yang didapatkan masih belum menyeluruh dan konsisten. Oleh karena itu, penting 
dilakukannya meta analisis untuk mengevaluasi efek CBT terhadap kecemasan yang dialami penderita bipolar.

\section{METODE PENELITIAN \\ Partisipan}

Partisipan yang akan digunakan adalah penderita bipolar yang memiliki komorbid kecemasan. Bipolar yang dipilih adalah bipolar I dan II yang secara teori memiliki komorbid kecemasan hingga 75\% penderitanya (American Psychiatric Association, 2013). Partisipan hanya boleh memiliki gangguan bipolar I atau II sebagai gangguan utamanya. Partisipan yang akan diikut sertakan juga harus memiliki rentang usia antara 18-65 tahun karena sesuai dengan kriteria kemunculan pertama kali pada penderita bipolar (American Psychiatric Association, 2013). Intervensi yang digunakan adalah cognitive behavioral therapy (CBT). Hal ini dikarenakan CBT memiliki efektivitas yang sudah terbukti signifikansinya dalam menangani pasien bipolar dan juga pasien pasien kecemasan secara terpisah. CBT yang digunakan adalah CBT standar tanpa adanya penambahan intervensi lain atau CBT yang dimodifikasi, seperti contoh CBT transdiagnostik disebut unified protocol (UP) dan Mindfulness CBT. Hasil yang dicari dalam setiap penelitian yang dianalisis adalah efek dari intervensi CBT pada gejala kecemasannya. Setiap penelitian harus memiliki target untuk menurunkan gejala kecemasan pada bipolar bukan sebaliknya yaitu intervensi terhadap bipolar yang secara beriringan juga menurunkan gejala kecemasannya. Hal ini karena didasarkan pada latar belakang bahwa masih minimnya intervensi psikologis terhadap kecemasan pada bipolar dan ingin melihat CBT sebagai salah satu psikoterapi yang tersedia untuk mengatasi permasalahan ini.

\section{Pengumpulan Data}

Data diambil dari berbagai data base yaitu APA Psycnet, Cochrane library, PubMed, Google scholar, Proquest, Grey literature (clinicaltrials.gov) untuk mengumpulkan artikel yang diperlukan hingga 31 Mei 2020. Pencarian menggunakan pengkombinasian kata kunci yaitu cognitive behavioral, cognitive behavioral therapy, anxiety, generalized anxiety disorder, panic disorder, phobia, phobic disorder, social anxiety disorder, obsessive compulsive disorder, post traumatic stress disorder, bipolar, bipolar disorder, bipolar depression atau mania, comorbid, comorbidity. Kata kunci ini kemudian diubah menjadi MeSH (Medical Subject Headings) yang bertujuan agar pencarian kata kunci lebih terarah dan terstruktur serta mencegah ada artikel yang terlewat dari pencarian. Setelah itu, artikel kembali disortir menggunakan diagram PRISMA. Kriteria inklusi dari penelitian ini adalah studi primer yang menggunakan teknik eksperimen intervensi CBT yang menargetkan gangguan komorbid kecemasan terhadap subjek penelitian yang mengalami gangguan bipolar I dan II sebagai diagnosa utama. Penelitian primer juga harus menggunakan alat ukur kecemasan sebelum dan sesudah intervensi

\section{Pengolahan Data}

Data diolah menggunakan pendekatan fixed effects model. Data dimasukkan dan dianalisis menggunakan Comprehensive Meta Analysis (CMA) software (Borenstein et al., 2014). Penggunaan software ini bertujuan untuk mengkomputasi nilai effect size, funnel plot dan nilai heterogenitas studi. Dengan demikian uji efek treatment CBT untuk kecemasan dapat diketahui dengan jelas. Selain itu, dapat diketahui pula bias publikasi, dan heterogenitas studi untuk menilai gambaran varians data yang di dapatkan 


\section{Gambar 1}

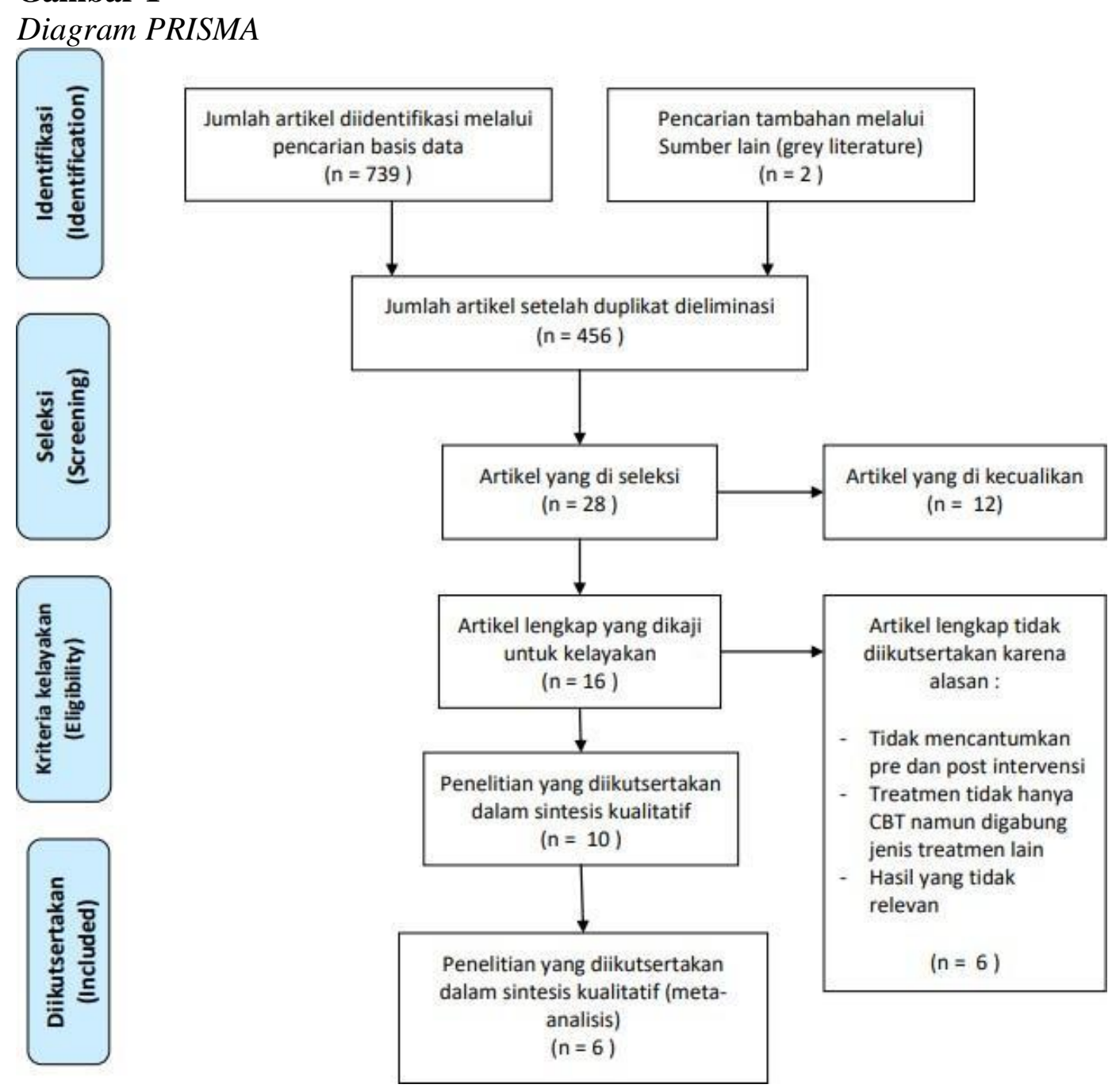

\section{HASIL DAN PEMBAHASAN}

Pencarian dan penyaringan literatur menghasilkan 6 studi yang memiliki rentang tahun dari 20042015. Perlu menjadi perhatian bahwa hasil ini merupakan hasil murni pencarian data tanpa dibatasi tahun publikasi. Partisipan yang diperoleh sebanyak 67 orang yang terdiri dari penderita bipolar yang mengalami komorbid kecemasan. Kecemasan yang dialami beragam yaitu sebagian besar subjek (44 orang) memiliki PTSD dan 19 orang memiliki diagnosa gangguan kecemasan sosial, serta 4 orang dengan gangguan kecemasan umum. Usia partisipan memiliki rentang antara 18 tahun hingga 64 tahun.

Desain penelitian dari studi yang digunakan adalah RCT (1 studi), Pilot study (2 studi), dan single case study (3). Biasanya, untuk mendapatkan hasil yang lebih dapat diandalkan, meta-analisis terutama dilakukan pada uji coba terkontrol secara acak (RCT), yang memiliki bukti tingkat tinggi (Uetani et al., 2009 dalam Ahn \& Kang, 2018). Bukti tingkat tinggi disini, merujuk pada bukti terhadap hubungan kausal yang jelas antara intervensi dengan variabel yang terukurnya. Namun, studi terkontrol non-acak (non RCT) yang berkualitas tinggi dapat menghasilkan hasil yang hampir serupa mendekati hasil temuan di RCT. Kualitas uji coba mungkin memiliki dampak yang lebih besar pada ukuran efek pengobatan daripada pengacakan saja, sehingga menunjukkan bahwa pengacakan tidak boleh dilihat sebagai proksi yang dapat diandalkan untuk kualitas keseluruhan 
(Ferriter \& Huband, 2005). Sehingga walaupun penelitian yang ditemukan tidak seluruhnya menggunakan RCT, namun penelitian meta analisis ini masih dapat dilakukan dengan baik.

Studi yang ditemukan, terdapat beragam diagnosa pada masing-masing subjek yang digunakan dalam penelitian primer tersebut. Oleh karena itu, pengukuran juga dilakukan dengan alat ukur yang berbeda. Diketahui untuk 3 penelitian yang memiliki subjek dengan diagnosa kecemasan berupa PTSD (Hamblen et al., 2004; Mueser et al., 2008; dan Rosenberg et al., 2004) menggunakan alat ukur CAPS (Clinician Administered PTSD Scale). Alat ukur CAPS ini sudah terbukti memiliki reliabilitas yang tinggi yaitu sebesar $(\alpha=.97)$. Sedangkan untuk 1 penelitian lain yang juga memiliki subjek PTSD (Lu et al., 2009) menggunakan alat ukur PCL (PTSD checklist). Alat ukur PCL ini memiliki nilai reliabilitas test retest dan validitas convergent yang tinggi. Walaupun tidak disebutkan koefisien reliabilitasi dalam penelitian tersebut untuk alat ukur PCL ini, namun sumber lain pada tahun yang sama menyebutkan bahwa alat ukur ini memiliki reliabilitas sebesar $(\alpha=.92)$ yang diartikan sebagai reliabilitas yang tinggi (Kivisto et al., 2009).

Sedangkan untuk penelitian dengan subjek yang memiliki gangguan kecemasan sosial (Queen et al., 2015), penelitian tersebut menggunakan alat ukur SPIN (Social Phobia Inventory) yang sudah terbukti memiliki reliabilitas yang tinggi $(\alpha=.92)$. Kemudian untuk penelitian yang menggunakan subjek dengan gangguan kecemasan umum (Thienot et al., 2013), digunakan alat ukur QIA (Le Questionnaire sur l'inquiétude et l'anxiété) yang berbahasa Perancis dengan reliabilitas tes retest yang juga tinggi, namun tidak disebutkan berapa koefisiennya dalam penelitian Thienot et al, 2013 tersebut. Penelitian ini juga menggunakan PSWQ (Penn State Worry Questionnaire) yang memiliki koefisien test retest sebesar $(\mathrm{r}=0,82)$ dan internal konsistensi $(\alpha=.92)$ yang artinya memiliki reliabilitas alat ukur sangat tinggi.

Berdasarkan hasil 6 studi ditemukan bahwa intervensi yang digunakan sama yaitu CBT. Perbedaan terdapat pada lama sesi dan panjangnya sesi. Setiap penelitian juga memberikan hasil yang sama yaitu adanya penurunan gejala kecemasan yang diukur menggunakan alat ukur kecemasan. Setiap penelitian juga melakukan follow up yang secara keseluruhan dilakukan pada waktu 1, 3 dan 6 bulan dari waktu selesai intervensi. Secara lengkap bisa dilihat pada tabel 1.

Hasil analisa uji hipotesis ini ditemukan bahwa keseluruhan artikel memiliki nilai uji hipotesis yang signifikan karena semua artikel memiliki nilai $\mathrm{p}>0,05$. Perbedaan rentang nilai $\mathrm{p}$ disebabkan karena adanya perbedaan jumlah subjek. Oleh karena hasil semua artikel menunjukan hasil yang signifikan, maka dilanjutkan dengan mensintesis dan menganalisa effect size yang dimiliki.

Berdasarkan hasil analisa artikel yang ditemukan, tidak semua artikel mencantumkan nilai effect size, sehingga perlu ada penghitungan secara manual dimulai dari menghitung nilai mean dan standar deviasi mean untuk mencari effect size yang diperlukan. Terdapat 1 artikel (Thienot et al., 2013) yang menggunakan 2 skala untuk mengukur pre dan post treatment sehingga perlu dilakukan rata-rata effect size dari 2 skala untuk mendapatkan 1 effect size pada artikel tersebut. Effect size yang dicari adalah dengan menggunakan Hedges' g dengan rumusan : 
Tabel 1

$$
(M 1-M 2) /(S D \text { Pooled })
$$

Gambaran Hasil Pencarian Literatur

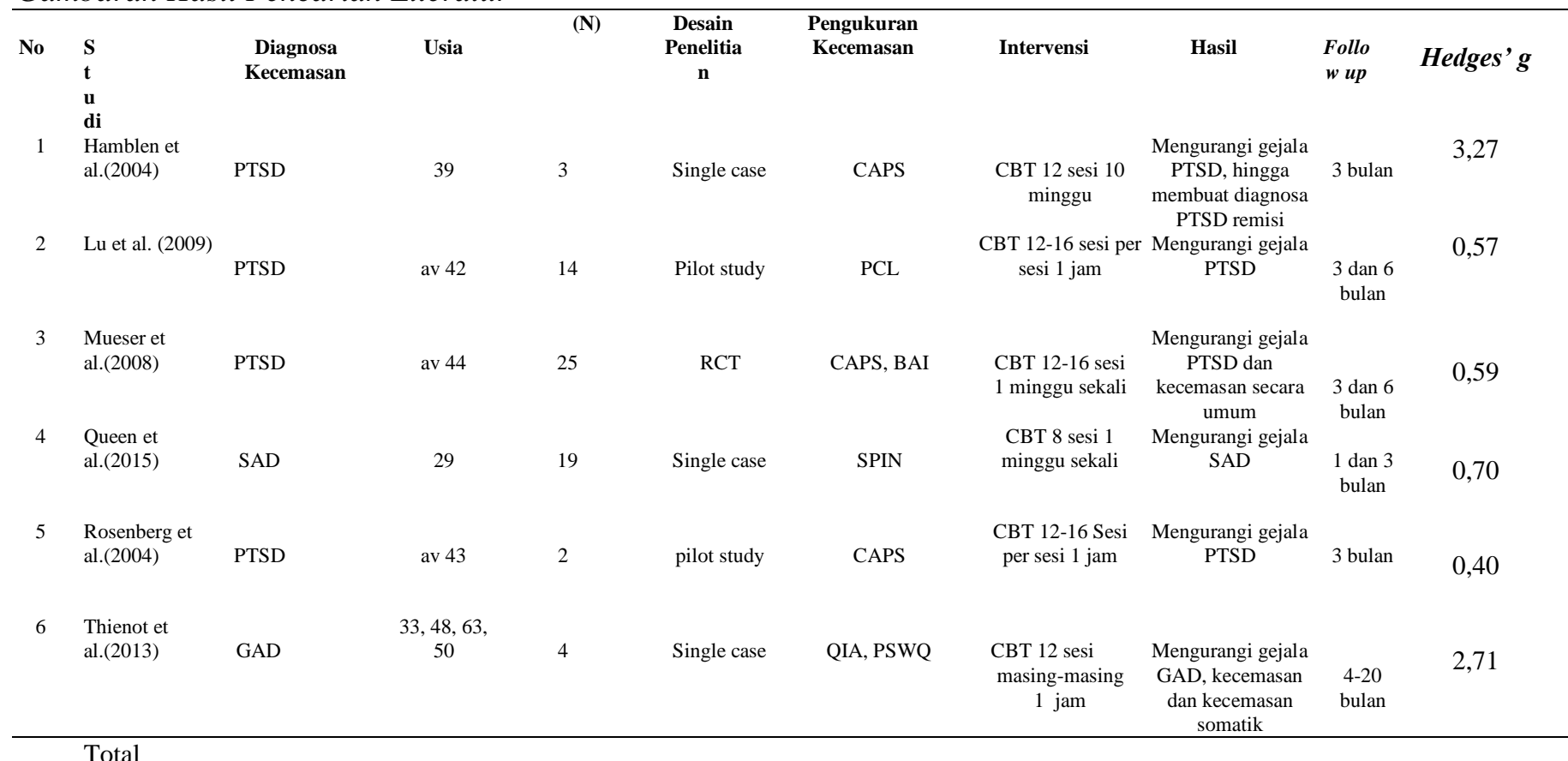

Setelah itu masing-masing nilai yang ditemukan di input kedalam program CMA dan menghasilkan nilai effect size untuk studi ini. Nilai effect size adalah sebesar 0,89 dengan $\mathrm{p}<0.04$. Interpretasi Hedges'g memiliki kesamaan interpretasi dengan persamaan effect size lainnya yaitu $0,2=$ efek kecil; 0,5 efek sedang; 0,8 efek besar. Dari norma tersebut dapat ditarik kesimpulan interpretasi bahwa ada 1 studi memiliki efek rendah (Rosenberg et al, 2004); 3 studi memiliki efek sedang (Lu et al, 2009; Mueser et al, 2008; Queen et al, 2015); dan 2 studi memiliki efek yang besar (Hamblen et al, 2004; dan Thienot, 2013). Diketahui dari hasil di atas terdapat 2 hasil effect size yang sangat besar $>1$ pada nilai Hedges g yaitu 3,27 (Hamblen et al., 2004) dan 2,71 (Thienot et al., 2013) pada masing-masing studi. Hal ini mengindikasikan perbedaan hasil yang besar antara sebelum dan setelah menerima intervensi.

Uji heterogenitas menunjukan $\mathrm{I}^{2}$ senilai $61,01(61,01 \%)$ hal ini menyatakan bahwa variablitas study dibawah angka $75 \%$ dan $\mathrm{p}<0,05$ hal ini menunjukan diterimanya $\mathrm{H} 0$ yaitu tidak ada perbedaan dalam studi. Dengan kata lain, studi bersifat homogen. Oleh karena itu, pemilihan fixed effect merupakan sebuah pilihan yang tepat karena di asumsikan bahwa semua studi dalam meta-analisis memiliki ukuran efek yang sama (benar) (Borenstein et al, 2011). Q value adalah statistik chi-squared dan df adalah derajat kebebasannya (Higgins 2002, Higgins 2003). Hal ini menggambarkan persentase variabilitas dalam perkiraan efek yang disebabkan oleh heterogenitas daripada kesalahan pengambilan sampel (kesempatan). 
Funnel Plot of Standard Error by Std diff in means

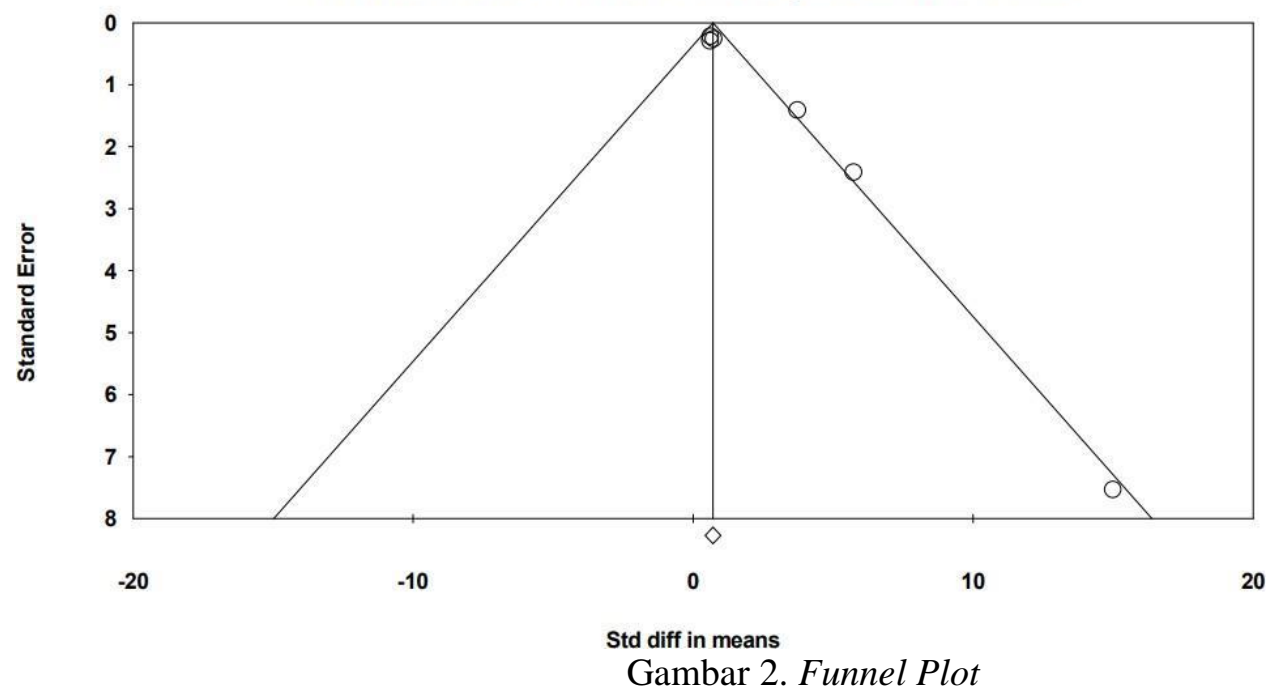

\begin{tabular}{|c|c|c|c|c|c|c|c|}
\hline \multirow[t]{2}{*}{$\underline{\text { Study name }}$} & \multicolumn{5}{|c|}{ Statistics for each study } & \multirow[b]{2}{*}{ Z-Value } & \\
\hline & $\begin{array}{l}\text { Std diff } \\
\text { in means }\end{array}$ & $\begin{array}{c}\text { Standard } \\
\text { error }\end{array}$ & Variar & $\begin{array}{c}\text { Lower } \\
\text { limit }\end{array}$ & $\begin{array}{l}\text { Upper } \\
\text { limit }\end{array}$ & & \\
\hline Hamblen et al & 5,730 & 2,410 & 5,806 & 1,008 & 10,453 & 2,378 & 0 \\
\hline Lu et al & 0,610 & 0,291 & 0,085 & 0,039 & 1,180 & 2,095 & 0,0 \\
\hline Mueser et al & 0,618 & 0,218 & 0,048 & 0,190 & 1,046 & 2,832 & 0,0 \\
\hline Queen et al & 0,733 & 0,258 & 0,067 & 0,227 & 1,240 & 2,838 & 0,0 \\
\hline Rosenberg et al & 14,994 & 7,530 & 56,706 & 0,235 & 29,753 & 1,991 & 0,0 \\
\hline Thienot et al & $\begin{array}{l}3,727 \\
0,707\end{array}$ & $\begin{array}{l}1,409 \\
0,144\end{array}$ & $\begin{array}{l}1,986 \\
0,021\end{array}$ & $\begin{array}{l}0,965 \\
0,426\end{array}$ & $\begin{array}{l}6,489 \\
0,989\end{array}$ & $\begin{array}{l}2,644 \\
4,924\end{array}$ & 0,0 \\
\hline
\end{tabular}

Gambar 3. Scatter Plot

Statistik funnel plot dan fail-safe N digunakan untuk mengestimasi bias publikasi (Egger et al., 1997). Pada gambar (Gambar 4.1) terdapat funnel plot yang merupakan sebaran studi individual yang menggambarkan ketepatan dan hasil dari treatment pada masing-masing studi. Terlihat bahwa scatter plot menunjukan persebaran yang skewed yang memiliki arti adanya data yang memiliki effect yang tidak terdistribusi normal dalam scatterplot tersebut. Namun dapat terlihat bahwa studi yang memiliki effect size besar berada di puncak dari piramidnya. Uji Fail Safe N berdasarkan uji signifikansi yang mengkombinasikan $\mathrm{p}$ values dari masing-masing studi. Pada prakteknya, semula dimasukan kesimpulan dari efek yang didapatkan, kemudian memasukan $\mathrm{p}$ value untuk efek kesimpulan tersebut. Pada tabel ditemukan bahwa nilai $\mathrm{z}$ adalah 6,03 yang mengindikasikan bahwa skor terstandar yang diperlukan untuk mencapai signifikansi maksimal adalah sejumlah 6.03 tersebut.

\section{KESIMPULAN DAN SARAN}

Dalam penelitian ini, didapatkan 6 studi yang secara sistematis meninjau dampak CBT terhadap gejala kecemasan untuk penderita bipolar. Secara keseluruhan, meta-analisis ini menghasilkan lebih banyak data daripada penelitian primer yang digunakan. Hasil yang didapatkan menunjukan bahwa 6 studi yang digunakan bersifat homogen. Studi ini menemukan bahwa efektivitas CBT yang secara kualitatif dinilai tinggi, dibuktikan dengan uji signifikansi dan uji effect size untuk mengetahui seberapa signifikan dan kekuatan efek CBT itu sendiri. 
Berdasarkan uji statistik ditemukan bahwa signifikansi seluruh studi adalah tinggi dengan nilai keseluruhan effect size mencapai $g=0,89$ dengan interpretasi efek tinggi. Sehingga dari data penemuan ini dapat diambil kesimpulan bahwa CBT efektif dalam mengatasi kecemasan pada penderita bipolar.

Kriteria sampling subjek pada penelitian primer yang digunakan masih belum bisa memastikan adanya keseragaman tingkat mood pada partisipan. Kedepannya, penelitian bisa fokus terhadap kestabilan mood serta variabel lain yang lebih luas, seperti contoh obat yang dikonsumsi. Variabel lain yang dapat terkontrol dengan baik, tentunya bisa mengoptimalkan penarikan kesimpulan efikasi dari CBT. Untuk meminimalisir terkontaminasinya penarikan kesimpulan, penelitian ini menetapkan kriteria inklusi yang cukup ketat. Kriteria inklusi yang tinggi membuat jumlah studi yang digunakan untuk analisa menjadi sangat terbatas dan menjadikan jumlah subjek yang terbatas pula. Namun demikian, kriteria inklusi tersebut membuat penelitian ini berfokus pada hasil CBT yang menargetkan gejala kecemasan pada penderita bipolar sehingga dapat diambil kesimpulan yang jelas dan bukan dikarenakan variabel ekstra lainnya.

\section{REFERENSI}

Adriani, S. N., \& Satiadarma, M. (2011). Efektivitas art therapy dalam mengurangi kecemasan pada remaja pasien leukemia. Indonesian Journal of Cancer, 5(1).

Ahn, E., \& Kang, H. (2018). Introduction to systematic review and meta-analysis. Korean Journal of Anesthesiology, 71(2), 103-112. https://doi.org/10.4097/kjae.2018.71.2.103

American Psychiatry Association. (1994). Diagnostic and statistical of mental disorders IV. American Psychiatric Pub Inc.

American Psychiatry Association. (2013). Diagnostic and statistical of mental disorders V. American Psychiatric Association

Bellani, M., Hatch, J. P., Nicoletti, M. A., Ertola, A. E., Zunta-Soares, G., Swann, A. C., Brambilla, P., \& Soares, J. C. (2012). Does anxiety increase impulsivity in patients with bipolar disorder or major depressive disorder?. Journal of psychiatric research, 46(5), 616-621

Borenstein, M., Hedges, L. V., Higgins, J. P., \& Rothstein, H. R. (2011). Introduction to metaanalysis. John Wiley \& Sons.

Borenstein, M., Hedges, L., Higgins, J., \& Rothstein, H. (2014). Comprehensive meta analysis V3. Englewood Cliffs, NJ: Biostat.

Deckersbach, T., Peters, A. T., Sylvia, L., Urdahl, A., Magalhães, P. V. S., Otto, M. W., Frank, E., Miklowitz, D. K., Berk, M., Kinrys, G., \& Nierenberg, A. (2014). Do comorbid anxiety disorders moderate the effects of psychotherapy for bipolar disorder? Results from STEPBD. American Journal of Psychiatry, 171(2), 178- 186. https://doi:10.1176/appi.ajp.2013.13020225

Ellard, K. K., Bernstein, E. E., Hearing, C., Baek, J. H., Sylvia, L. G., Nierenberg, A. A., Barlow, D. H., \& Deckersbach, T. (2017). Transdiagnostic treatment of bipolar disorder and comorbid anxiety using the unified protocol for emotional disorders: A pilot feasibility and acceptability trial. Journal of affective disorders, 219, 209-221.)

Ellard, K. K., Gosai, A. G., Bernstein, E. E., Kaur, N., Sylvia, L. G., Camprodon, J. A., Dougherty, D. D., Nierenberg, A. A., \& Deckersbach, T. (2018). Intrinsic functional neurocircuitry associated with treatment response to transdiagnostic CBT in bipolar disorder with anxiety. Journal of affective disorders, 238, 383-391 
Ferrari, A. J., Stockings, E., Khoo, J. P., Erskine, H. E., Degenhardt, L., Vos, T., \& Whiteford, H. A. (2016). The prevalence and burden of bipolar disorder: Findings from the Global Burden of Disease Study 2013. Bipolar Disorders, 18(5), 440-450. doi:10.1111/bdi.12423

Ferriter, M., \& Huband, N. (2005). Does the non-randomized controlled study have a place in the systematic review? A pilot study. Criminal behaviour and mental health: $C B M H, 15(2)$, 111-120. https://doi.org/10.1002/cbm.43

Jones, S., Riste, L., Barrowclough, C., Bartlett, P., Clements, C., Davies, L., Holland, F., Kapur, N., Lobban, F., Long, R., Morriss, R., Peters, S., Roberts, C., Camacho, E., Gregg, L., \& Morriss, R. (2018). Psychological treatment of anxiety in bipolar disorder. In Reducing relapse and suicide in bipolar disorder: practical clinical approaches to identifying risk, reducing harm and engaging service users in planning and delivery of care-the PARADES (Psychoeducation,Anxiety, Relapse, Advance Directive Evaluation and Suicidality) programme. NIHR Journals Library. https://10.3310/pgfar06060

Kinrys, G., Bowden, C. L., Nierenberg, A. A., Hearing, C. M., Gold, A. K., Rabideau, D. J., ... \& Tohen, M. (2019). Comorbid anxiety in bipolar CHOICE: Insights from the bipolar inventory of symptoms scale. Journal of affective disorders, 246, 126-131. https://www.researchgate.net/publication/329749786_Comorbid_Anxiety_in_Bipolar_C HOICE_Insights_from_the_Bipolar_Inventory_of_Symptoms_Scale

Kivisto, A. J., Moore, T. M., Elkins, S. R., \& Rhatigan, D. L. (2009). The effects of PTSD symptomatology on laboratory-based aggression. Journal of Traumatic Stress: Official Publication of The International Society for Traumatic Stress Studies, 22(4), 344-347.

Latalova, K., Prasko, J., Grambal, A., Havlikova, P., Jelenova, D., Mainerova, B., Kamaradova, D., Ociskova, M., Sedlackova, Z., \& Sandoval, A. (2013). Bipolar disorder and anxiety disorders. Neuro endocrinology letters, 34(8), 738-744.

Lee, Y. H. (2019). Strengths and Limitations of Meta-Analysis. The Korean Journal of Medicine, 94(5), 391-395. https://doi.org/10.3904/kjm.2019.94.5.391

Loftus, J., Scott, J., Vorspan, F., Icick, R., Henry, C., Gard, S., ... \& Etain, B. (2020). Psychiatric comorbidities in bipolar disorders: An examination of the prevalence and chronology of onset according to sex and bipolar subtype. Journal of Affective Disorders, 267, 258-263.

Mitchell, P. B. (2015). Bipolar disorder and anxiety: a comorbidity needing better treatments. The lancet. Psychiatry, 2(8), 671-672

Nabavi, B., Mitchell, A. J., \& Nutt, D. (2015). A Lifetime Prevalence of Comorbidity Between Bipolar Affective Disorder and Anxiety Disorders: A Meta-analysis of 52 Interview-based Studies of Psychiatric Population. EBioMedicine, 2(10), 1405-1419. https://doi.org/10.1016/j.ebiom.2015.09.006

Pavlova, B., Perlis, R.H., Mantere, O., Sellgren, C.M., Isometsa, E., Mitchell, P. B., Alda, M., Uher, R., (2017). Prevalence of current anxiety disorders in people with bipolar disorder during euthymia: A meta-analysis. Psychological medicine 47, 1107-1115. practice. Guilford Press.

Spoorthy, M. S., Chakrabarti, S., \& Grover, S. (2019). Comorbidity of bipolar and anxiety disorders: An overview of trends in research. World journal of psychiatry, 9(1), 7.

Stone, D. L., \& Rosopa, P. J. (2017). The advantages and limitations of using meta-analysis in human resource management research. Human Resource Management Review, 27(1), 17. https://doi.org/10.1016/j.hrmr.2016.09.001

Subroto, U., Satiadarma, M. P., \& Wati, L. (2017). Pengaruh urutan kelahiran pada kecemasan mahasiswa sekolah tinggi ilmu komunikasi X Jakarta. Jurnal Muara Ilmu Sosial, Humaniora, dan Seni, 1(1), 311-318. 
Van Aert, R. C. M., Wicherts, J. M., \& van Assen, M. A. L. M. (2019). Publication bias examined in meta-analyses from psychology and medicine: A meta-meta-analysis. PLOS ONE, 14(4), e0215052. https://doi.org/10.1371/journal.pone.0215052

Van Dis, E. A., Van Veen, S. C., Hagenaars, M. A., Batelaan, N. M., Bockting, C. L., Van Den Heuvel, R. M., Cuijpers, P., \& Engelhard, I. M. (2020). Long-term outcomes of cognitive behavioral therapy for anxiety-related disorders: A systematic review and metaanalysis. JAMA psychiatry, 77(3), 265-273.

Wenzel, A., Dobson, K. S., \& Hays, P. A. (2016). Cognitive behavioral therapy techniques and strategies. American Psychological Association.

Wilkowska, A., \& Cubała, W. J. (2019). Clozapine as transformative treatment in bipolar Patients. Neuropsychiatric disease and treatment, 15, 2901- 2905. https://doi.org/10.2147/NDT.S227196 